\title{
Writing and Reporting of Scalp Electroencephalography
}

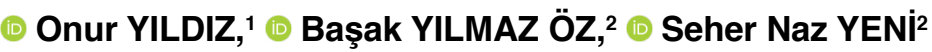

'Department of Neurology, Ondokuz Mayıs University Faculty of Medicine, Samsun, Turkey

${ }^{2}$ Department of Neurology, İstanbul University-Cerrahpaşa Faculty of Medicine, İstanbul, Turkey

\section{Summary}

Electroencephalography (EEG) is the gold standard for analyzing electrophysiological processes involved in epilepsy, as well as in several other dysfunctions of the central nervous system. Firstly, to properly interpret the EEG record, one must clearly have in mind the elements of a normal EEG. Secondly, to assist in producing useful information for clinical and research purposes, it is recommended to use standardized terminologies and to follow an orderly EEG reporting approach. The EEG report gives a clinical interpretation in light of the diagnosis and must meet the expectations of the clinician. The EEG terminology should be understandable to other physicians who are not specialized in EEG. The review aims to provide a standardized format for reporting the results of adult routine scalp EEG.

Keywords: Electroencephalography; reporting; scalp.

Cite this article as: Yıldız O, Yılmaz Öz B, Yeni SN. Saçıı Deri Writing and Reporting of Scalp Electroencephalography. Epilepsi 2021;27:1-7.

\section{Giriş}

Elektroensefalografi (EEG) raporu, değerlendirilen EEG trasesinin en öz ve anlaşılır biçimde, tetkiki isteyen kişiye yansıtılmasıdır. Klinik ve araştırma amaçlı yararlı bilgiler üretmeye yardımcı olması için, raporlamada standart terminoloji ve düzenli bir yaklaşım izlenmesi önerilir. Tetkiki isteyen hekim EEG'nin teknik yönleri ve terminoloji konusunda uzman olmayabilir ve bu nedenle rapor klinik sorulara net cevaplar vermeli ve kolayca anlaşılabilmelidir. Özetle bir EEG raporunun amacl; başka bir klinisyenin EEG traselerine bakmaksızın, yazılı rapordaki kaydın normalliği veya anormalliği, anormal ise derecesi ile ilgili bir sonuca varmasını mümkün kılan eksiksiz ve objektif bir rapor üretilmesidir. ${ }^{[1]}$

Bu derlemenin amacı, yetişkin rutin saçlı deri EEG sonuçlarını raporlamak için standart bir format sağlamaktır ve Amerikan Klinik Nörofizyoloji Derneği'nin EEG raporlama kılavuzu

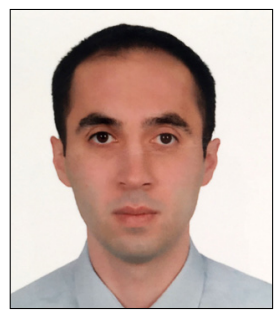

Corresponding author Onur YILDIZ, M.D. e-mail dronuryildiz@hotmail.com

Received 16.01.2020

Accepted 11.03.2020

Online date 25.01.2021

Content of this journal is licensed under a Creative Commons Attribution-NonCommercial 4.0 International License.

Dr. Onur YILDIZ
(Tatum, 2016) ${ }^{[2]}$ temel alınarak hazırlanmıştır. Rutin saçlı deri EEG raporlaması için standart format beş bölümden oluşmalıdır: geçmiş, teknik tanımlama, EEG tanımlanması, izlenim, klinik korelasyon.

Geçmiş- İlk bölüm, hastanın kişisel bilgileri ve sevk nedenini içermekle birlikte rutin saçlı deri EEG'nin yorumlanmasına yardımcı olan klinik bilgileri de içerir. Kişisel bilgiler kısmı en azından hasta adı ve soyadı, cinsiyeti, hastane kayıt ve/veya kimlik numarası, doğum tarihi ve kayıt esnasındaki yaşını içermelidir. Ardından hasta ilgili kısa tıbbi öykü, son nöbet tarihi, düzenli kullandığı antiepileptik ve psikotrop ilaçlar, nörogörüntüleme sonuçları ve eğer varsa kraniyal ameliyat bilgisi rapora eklenmelidir. ${ }^{[2]}$ Bölümün eksiksiz doldurulabilmesi için EEG isteğinde bulunan hekimin hastanın durumu ile ilgili bilgileri detaylı bir şekilde istek kağıdına yazması gerekmektedir. EEG okuyucusu yorumunu bu klinik bilgiler doğrultusunda yapmaya çalışacaktır. EEG istek sebebi ayrıca yazılmalıdır ve Tablo 1'deki endikasyonlardan biri seçilebilir. ${ }^{[3]}$

Teknik tanımlama- EEG raporunun bu bölümü hastanın EEG kaydı başlanılmadan önceki hazırlık döneminde yapılanları içermelidir. IIlk olarak EEG çekiminin kayıt tipi ve eş zamanlı video çekiminin olup olmadığının belirtilmesi ile başlanılmalıdır. Kayıt tipi örnekleri "rutin EEG, uyku EEG, kısa süreli video-EEG, uzun süreli video-EEG, yoğun bakım kayıt izlemi vb." şeklindedir. ${ }^{[3]}$ Elektrotların yerleşimi tanımlanırken standart uluslararası 10-20 (veya 10-10) sistemi veya diğer kayıt sistemleri, eğer mevcut ise ek elektrotlar (örn. 


\section{Saçlı Deri Elektroensefalografisi Yazımı ve Raporlanması}

\section{Özet}

Elektroensefalografi epilepside yer alan elektrofizyolojik süreçlerin yanı sıra santral sinir sisteminin diğer bazı işlev bozukluklarının analizi için altın standarttır. Öncelikle, kaydı doğru bir şekilde yorumlayabilmek için normal elektroensefalografi unsurlarını açıkça akılda tutmak gerekir. Klinik ve araştırma amaçlı yararlı bilgiler üretmeye yardımcı olması için, raporlamada standart terminoloji ve düzenli bir yaklaşım izlenmesi önerilir. Elektroensefalografi raporu, yönlendiren hekim tarafından yöneltilen sorular ışığında klinik bir yorum verir ve klinisyenin beklentilerini karşılamalıdır. Elektroensefalografinin terminolojisi, elektroensefalografide uzman olmayan diğer doktorlar tarafından anlaşılabilir olmalıdır. Bu derlemenin amacı, yetişkin rutin saçlı deri elektroensefalografi sonuçlarını raporlamak için standart bir format sağlamaktır.

Anahtar sözcükler: Elektroensefalografi; raporlama; saçlı deri.

T1/T2, sfenoidal veya subtemporal elektrotlar) ve kraniyum defektleri nedeniyle olan modifikasyonlar belirtilmelidir. Teknik açıklama örneği şu şekilde verilebilir: "Bu çekim eş zamanlı video çekimi içeren 21 kanallı dijital EEG kaydı ve tek kanallı elektrokardiyogramı içerir. Elektrotlar, 10-20 (veya 10-10) Uluslararası Sistemine göre yerleştirilmiştir."[2] Çalışmanın süresi yazılmalı ve eğer çekim süresi kısalmış veya uzamış ise sebebi belirtilmelidir. ${ }^{[4]}$

Hastanın çekim öncesindeki bilinç durumu, uyanıklığı ve kooperasyonu (uyanık, iyi koopere, kısmi koopere, koopere değil, uykulu, uykuda, yanıtsız, koma) not edilmelidir. ${ }^{[3]} \mathrm{Bu}$ bilgi EEG'nin yorumlanmasına ve elektroklinik korelasyonun oluşturulmasına yardımcı olur. EEG kaydı sırasında veya öncesinde premedikasyon yapılmış ise ilacı ve dozu içerecek şekilde rapora eklenmelidir (örn. "kayıttan önce diazepam $5 \mathrm{mg}$ verildi").[2] Açlık ve uyku deprivasyonu gibi fizyolojik faktörlerin varlığı mutlaka raporda belirtilmelidir. Uyku EEG çekimi esnasında uykunun spontan veya medikasyon ile ortaya çıkıp çıkmadığı raporda belirtilmelidir. ${ }^{[5]}$

Elektroensefalografi tanımlanması- Bu bölüm, mümkün olduğunca objektif bir şekilde, arka plandaki elektroserebral aktivitenin bir tanımını ve kayıtta izlenen anormal dalga formlarının tüm temel özelliklerini içermelidir. Amaç, EEG raporunu okuyan başka bir elektroenselografın "normal" veya "anormal" bir sonuca varmak için arka plan etkinliğinin ve EEG'nin en belirgin özelliklerinin eksiksiz, nesnel ve düzenli bir tanımını sağlamaktır. Bir anormallik tespit edildiğinde, anormallik derecesi belirtilmeli, normal değişkenler de tanımlanmalıdır. ${ }^{[2]}$ Kayıt süresince mevcut dalga formlarını açıklamak için teknik terminoloji ve metrikler kullanılmalıdır. ${ }^{[6]}$

Rutin saçlı deri EEG, posterior dominant ritim veya baskın zemin aktivitesinin tam bir açıklaması ile başlamalıdır. Arka plan aktivitesinin frekansı, amplitüdü, lokalizasyonu, sürekliliği, reaktivitesi, ritmisitesi ve simetrisi yazılmalıdır. Posterior dominant ritmin tanımlaması, hastanın en uyanık olduğu durumda frekans ( $\mathrm{Hz}$ veya $\mathrm{c} / \mathrm{s}$ ) ve amplitüd $(\mu \mathrm{V})$ birimleri ile belirtilmelidir. ${ }^{[2]}$ Amplitüd için "düşük $(<20 \mu \mathrm{V})$ ", "orta (20-70 $\mu \mathrm{V})$ " veya "yüksek (>70 $\mu \mathrm{V})$ " voltajlı gibi terimler kullanılabilir, ancak sayısal olarak ölçülmelidir. ${ }^{[3]}$ Her dalganın frekansı ve amplitüdü kayıt sırasında değişkenlik gösterdiği için tek bir frekans veya amplitüd değeri yerine daha geniş aralıkI olarak yazmak daha doğrudur (örn. 9-10 Hz, 60-70 $\mu \mathrm{V}$ ). ${ }^{[5]}$ Zemin aktivitesinin tanımlanmasında, göz açma-kapama ya da istemli ekstremite hareketine olan cevap yer almalıdır. Bu durumu açıklarken, yanıtın simetrik mi yoksa asimetrik mi olduğu, tam veya inkomplet baskılanma mı veya etkilerin sürdürülüp sürdürülmediği sorularına cevap vermelidir. ${ }^{[4]}$ Eğer kayıt hemisferler arası asimetri gösteriyor ise her bir hemisferin özellikleri ayrı ayrı tanımlanmalıdır. Özellikle ensefalopati veya koma olgularında EEG reaktivitesini değerlendirmek için, hangi ek stimülasyon yöntemlerinin (dokunma, ses, el ile göz açma, burun gıdıklaması, sternal basınç uygulama) gerçekleştirildiği ve buna olan yanıtı belirtmek

Tablo 1. Elektroensefalografi endikasyonları

\begin{tabular}{ll}
\hline Epilepsi ilişkili endikasyonlar & Diğer tanısal endikasyonlar \\
\hline • Klinik epilepsi veya nöbet şüphesi & • Bilinç durumunda değişiklik \\
• Epilepsi tanısı konulmuş bir hastanın sınıflandırılması & • Ensefalit \\
• Nöbet paterninde değişiklikler & - Demans \\
• Nonkonvülzif status epileptikus şüphesi & - Serebrovasküler hastalık \\
• Status epileptikusun izlenmesi & - Beyin ölümü \\
- Antiepileptik tedavi kesim planı & • Psikojenik nonepileptik nöbetler \\
• Cerrahi değerlendirme & \\
\hline
\end{tabular}


önemlidir. ${ }^{[4]}$ Bazı normal kayıtlarda dahi net bir şekilde tanımlanmış bir dominant ritim bulunmayabilir ve böyle bir durum raporda belirtilmelidir. Nondominant aktivitelerin tanımlanmasında dominant aktivitelerin tanımlanmasındakine benzer özellikler kullanılır. ${ }^{[1]}$ Voltaj atenüasyonu veya augmentasyonu, bursit süpresyon paterni veya elektroserebral inaktivite gibi görülen özel arka plan aktiviteleri, normal zemin aktivitesini tarif etmek için kullanılan aynı terminoloji kullanılarak detaylandırılmalıdır. ${ }^{[2]}$

Zemin aktivitesinin tanımlanmasının ardından belirgin anormal özellikler not edilmelidir. Paroksismal anormallikler çoğu zaman öznel bir şekilde ifade edilir ve bireysel raporlama tasarımlarına göredir. Bildirilen bir anormalliğin anlık görüntülerinin EEG raporuna dahil edilmesi önerilir ve böylece anormallik olarak neyin tanımlandığının anlaşılmasını kolaylaştırır. İnteriktal epileptiform deşarjlar mevcutsa lokalizasyonu, morfolojisi (örn. diken, keskin, çoklu diken \pm yavaş dalga), paterni (örn. tekli, sürekli, rastgele, ritmik, periyodik) ve görülme sıklığı (örn. nadir, aralıklı, ara sıra, sık, sürekli) raporda belirtilmelidir. ${ }^{[2]}$ Tanımda ayrıca olayın $\mathrm{Hz}$ cinsinden frekansı, amplitüdü ve görülme süresi de eklenmelidir. Bir fokal anormallikten bahsederken, lokalizasyonu (örn. anterior temporal) veya daha net olarak bir elektrot yerleşimi (örn. T3) tanımlanmalıdır. ${ }^{[4]}$ Anormallik epizodik olduğunda, her epizot arasında periyodisitenin varlığına veya yokluğuna dikkat edilmeli, epizotlar arası süre belirtilmelidir. ${ }^{[1]}$ Bilateral izlenen epileptiform olaylar tanımlanırken amplitüd simetrisi (örn. >\%50), senkroni (örn. primer bilateral senkroni veya sekonder bilateral senkroni) ve olayın zamansal paterni (örn. bursitler şeklinde, uzun süreli devam eden ya da sporadik) dahil edilmelidir. ${ }^{[2]}$ Yavaş dalgalar görüldüğünde dalganın şekli, frekansı, amplitüdü, lokalizasyonu, ritmi, simetrisi, sürekli ya da aralıklı olup olmadığı, uykuda veya uyanıklıkta görülüp görülmemesi ve hastanın yaşı için normal ya da anormallik derecesi not edilmelidir. ${ }^{[5]}$ Tüm patolojik aktivitelerin görülme sıklığı tanımlanır iken "nadir $(<1$ saat), aralıklı ( $1 / 5$ dakika-1 saat), ara sıra (1 dakika-1/5 dakika), sık ( $1 / 10$ saniye-1 dakika), çok sık-sürekli (>1/10 saniye)" ifadeleri kullanılabilir. ${ }^{[3]}$

Video kaydı, rutin saçlı deri EEG gerçekleştirmek için kullanılan çoğu sistemin rutin bir parçasıdır. Rapora video açıklamalarının dahil edilmesi, elektroklinik nöbetler ve artefaktların değerlendirmesi amacıyla önemlidir. Bir elektroklinik nöbet varlığında o esnada izlenen görüntüler tanımlanmalı ve raporun klinik izlenim kısmına eklenmelidir. Klinik olayın tanımı, süresi, hastanın yanıt ve farkındalık düzeyi Uluslararası Epilepsi Nöbet Sınıflandırma Sisteminin kullandığı terminoloji doğrultusunda yazılmalıdır. ${ }^{[2]}$ Epileptik nöbet tipleri mevcut "The International League Against Epilepsy (ILAE)" nöbet sınıflaması (Fisher ve ark., 2017), ${ }^{[7]}$ semiyoloji ise ILAE iktal semiyoloji için tanımlayıcı terminoloji sözlüğüne (Blume ve ark., 2001) ${ }^{[8]}$ göre tanımlanmalıdır. ${ }^{[3]}$

EEG kaydı sırasında ulaşılan tüm uyku aşamaları ve mimarisi normal olduğu koşullarda dahi rapora eklenmelidir. Verteks keskini ve iğcikler gibi normal uyku elemanlarında asimetri veya azalma gibi anormal paternlere dikkat edilmelidir. Uykuda görülen paroksismal veya epileptiform anormallikler açık bir şekilde yazılmalıdır. Uykuda görülen ancak klinik önemi tam olarak bilinmeyen $14 \& 6 \mathrm{~Hz}$ dikenler, $6 \mathrm{~Hz}$ diken ve yavaş dalgalar, küçük keskin diken ve midtemporal teta gibi epileptiform olmayan aktiviteler ise tercihen yazılabilir. ${ }^{[5]}$

Hiperventilasyon ve aralıklı fotik stimülasyon, rutin saçlı deri EEG sırasında anormallikleri tetiklemek için kullanılan rutin aktivasyon yöntemleridir. Normal ve anormal cevaplar dahil olmak üzere, hiperventilasyonun ve fotik stimülasyonun etkileri tanımlanmalıdır. Hiperventilasyon veya fotik stimülasyon yapılamaz ise nedeni belirtilmelidir. Aktivasyon prosedürleri sırasında veya sonrasında rutin saçlı deri EEG'de yavaşlama veya herhangi bir epileptiform bozukluk ile karşılaşılırsa anormalliklerin aktivasyon yöntemi ile olan ilişkisi tanımlanmalıdır. Hiperventilasyon esnasında özellikle genç hastalarda görülen, jeneralize yavaşlama gibi normal fizyolojik yanıtlar iyi değerlendirilmeli ve patolojik olarak yorumlanmamalıdır. ${ }^{[5]}$ Fotik stimülasyon sırasında eğer bir anormallik ortaya çıktı ise hangi frekansta ortaya çıktığı ve göz açma-kapama ile olan ilişkisi raporda belirtilmelidir.

Elektroensefalograf, klinik önemi göz önüne alındığında fizyolojik paternleri ve anlamı belirsiz paternleri rapora eklemelidir. Elektrokardiyografide (EKG) özellikle önemli bir anormallik varsa belirtilmeli ama iskemi gibi yorumlayıcı ifadelerden kaçınılmalıdır. ${ }^{[4]}$ Ayrıca tüm iktal nöbetlerde EKG şeridi gözden geçirilmeli ve anormallikler bildirilmelidir. ${ }^{[9]}$ Artefaktlar hemen hemen her rutin saçlı deri EEG'de mevcuttur. Serebral aktiviteyi taklit ettikleri zaman, sıra dışı veya aşırı olduklarında (trase ve elektrotların >\%50'si), kaydın yorumlanmasını engellediklerinden dolayı raporlanmalıdırlar. ${ }^{[2]}$

İzlenim- İzlenim (veya yorumlama), EEG bulgularının kısa bir özeti ve sentezidir. Öncelikle yönlendiren klinisyen için yazılmıştır ve bu nedenle mümkün olduğu kadar özlü olmalı ve herhangi bir klinisyen tarafından kolayca anlaşılabilir olmaIıdır. Başka bir EEG okuyucusunun kaydı kavrayabileceği ve daha sonraki bir tarihte raporu inceleyebileceği şekilde yazılmalıdır. Çoğu klinisyen, bir önceki bölümde anlatılan tanımlamaları okumaktan kaçınır, dolayısıyla izlenim bölümü anlaşılır ve kısa cümlelerle oluşturulmalıdır. Bu bölüm çok uzunsa ve klinik tablo ile alakalı görünmüyorsa, klinisyen ilgisini kay- 
bedecek ve kayıt raporu daha az kullanışlı hale gelecektir. ${ }^{[1]}$ ilk olarak kaydın "normal" mi yoksa "anormal" mi olduğuna dair net bir ifade ile başlanmalıdır. EEG anormal ol- duğunda, sonuçların basitleştirilerek ve anormalliklerin önem derecesine göre sıralanacak şekilde yazılması arzu edilir. Birkaç tür anormal özellik ile uğraşırken, kayıtta en

Tablo 2. Klinik korelasyon örnekleri*

- “Normal bir interiktal elektroensefalografi, epilepsi tanısını dışlamaz veya desteklemez."

- "Fokal yavaşlama, ipsilateral hemisferin ak maddesini içeren altta yatan bir lezyonu göstermektedir."

- "Zemin aktivitesinin difüz yavaşlaması (derecesi belirtilmeli), toksik-metabolik veya sistemik nedenlere bağlı difüz kortikal disfonksiyon, nörodejeneratif bozukluklar veya kortikal yaralanmalara bağlı görülebilir."

- "Jeneralize diken ve yavaş dalgalar, epilepsi tanısı olan bir hastada jeneralize bir mekanizma anlamına gelir, ancak aynı zamanda klinik nöbetlerden bağımsız olarak kalıtsal bir özelliği de temsil edebilir."

- "Sol anterior temporal diken dalgalar, epilepsi klinik tanısı olan bir hastada fokal hipersenkronizasyonu gösterir ve temporal lob kökenli fokal başlangıçlı nöbetler için yüksek risk taşır."

- “Normotermik kardiyak arrest sonrası bursit süpresyon paterni (anestezik ilaçların yokluğunda), nörolojik sonuçlar açısından kötü bir prognoz göstergesidir."

*Bu tablo "American Clinical Neurophysiology Society Guideline 7: guidelines for EEG reporting"den yararlanarak hazırlanmıştır.

Tablo 3. Elektroensefalografi (EEG) rapor basamakları

GEÇMiş

TEKNIK TANIM

EEG TANIMI

IZLENIM

KLINIK KORELASYON
1- Kişisel bilgiler: Adı-soyadı, cinsiyeti, kayıt numarası, doğum tarihi ve kayıt esnasındaki yaşı.

2- Kısa tıbbi geçmiş: Kısa tıbbi öykü, son nöbet tarihi, antiepileptik ve psikotrop ilaçlar, nörogörüntüleme sonuçları ve kraniyal cerrahi bilgisi.

3- İstek sebebi: Tablo 1'de gösterilmiştir.

1- EEG kayıt tipi: Rutin EEG, uyku EEG, kısa süreli video-EEG, uzun süreli video-EEG, yoğun bakım kayıt izlemi vb.

2- Kayıt özellikleri: "Bu çekim eş zamanlı video çekimi içeren 18 kanallı dijital EEG kaydı ve tek kanallı elektrokardiyogramı içerir. Elektrotlar, 10-20 Uluslararası Sisteme göre yerleştirildi."

3- Kayıt süresi: Çalışmanın süresi yazılmalı ve eğer çekim süresi kısalmış veya uzamış ise sebebi belirtilmeli.

4- Bilinç durumu ve uyanıklık: Uyanık, iyi koopere, kısmi koopere, koopere değil, uykulu, uykuda, yanıtsız, koma.

5- Fizyolojik durumu: Açlık, uyku deprivasyonu.

6- Premedikasyon: Çekim öncesi veya esnasında uygulanan ilaç dozu ile birlikte belirtilmeli.

1- Zemin aktivitesi ve reaktivitesi: Frekansı, amplitüdü, lokalizasyonu, sürekliliği, reaktivitesi, ritmisitesi ve simetrisi yazılmalı.

2- İnteriktal bulgular:

- Lokalizasyonu, morfolojisi (diken, keskin, çoklu diken \pm yavaş dalga), paterni (tekli, sürekli, rastgele, ritmik, periyodik) ve görülme sıklığı (nadir, aralıklı, ara sıra, sık, sürekli),

- Jeneralize aktivitelerde primer bilateral senkroni veya sekonder bilateral senkroni terimleri kullanılabilir.

3- İktal patern: EEG ve video görüntüleri tanımlanmalı.

4- Uykunun yeterliliği:Verteks keskini ve iğciklerde asimetri/azalma ve paroksismal veya epileptiform anormalliklerdeki artış değerlendirilmeli.

5- Hiperventilasyon ve IFS: Normal/anormal yanıt, yapılamaz ise sebebi belirtilmeli.

6- Fizyolojik paternler veya anlamı belirsiz paternler:

7- Artefakt: Trase ve elektrotların $>\% 50$ 'si etkilenmiş ise raporlanmalı.

"Bu EEG normaldir/anormaldir." şeklinde net bir ifade ile başlanılmalı.

Anormal ise en belirgin patolojiler önem sırasına göre sıralanmalı.

1- Normal:

2- Anormal: Tablo 2'de gösterilmiştir. 
belirgin olan iki veya üç ana özellikle sınırlı kalınmalıdır. İzlenimdeki tüm anormallikler tekrar sıralanırsa, daha önemli olanların vurgusu kaybedilir. Örneğin; (1) sol fokal temporal elektrografik nöbet, (2) sol anterior temporal diken ve yavaş dalga, (3) sol temporal delta yavaşlaması ve (4) zemin aktivitesinde hafif derecede yavaşlama, şeklinde bir izlenim kısmı oluşturulabilir. Eğer önceki EEG'ler mevcutsa, önceki izlenimlere göre karşılaştırma yapılabi$\operatorname{lir}^{[1,2,4]}$
Klinik korelasyon- Klinik korelasyon, EEG'nin nihai çevirisidir ve bu bölümde EEG okuyucusu bulgularının klinik tabloya uyup uymadığını tartışmalıdır. EEG'ye başvuru nedenine ve hasta yönetimine yardımcı olmak için tüm veriler birleştirilmelidir. Tercihen, "diken yavaş dalgalar" gibi daha evrensel olarak kullanılan terimler haricinde, birkaç teknik EEG terimini içermelidir ve bir pratisyen hekim veya hemşire gibi yardımcı bir sağlık çalışanı tarafından okunduğunda kolayca anlaşılmalıdır. ${ }^{[2,4]}$ Eğer EEG normal

Tablo 4. Anormal EEG örneği

\section{T.C. İstanbul Üniversitesi-Cerrahpaşa Cerrahpaşa Tıp Fakültesi}

Hasta Adı-Soyadı: B.D

Cinsiyet: $E$

Yaş: 16
Kayit tarihi: 04.01.2020

Rapor tarihi: 06.01.2010

H. Protokol No:

Tıbbi geçmiş: 15 gün önce jeneralize tonik klonik nöbet, son 6 aydır özellikle sabahları ortaya çıkan, kollarında ani sıçrama atakları. Beyin manyetik rezonans görüntülemesi normal.

İstek sebebi: Klinik epilepsi şüphesi, jüvenil miyoklonik epilepsi?

\section{TETKIK}

Kayıt tipi: Tetkik rutin uyanıklık ve 1 saat uyku amaçı çekilmiştir.

Kayıt özellikleri: Bu çekim eş zamanlı video çekimi içeren 18 kanallı dijital EEG kaydı ve tek kanallı elektrokardiyogramı içerir. Elektrotlar, 10-20 Uluslararası Sisteme göre yerleştirildi.

Bilinç durumu ve uyanıklık: Uyanık ve iyi koopere

Fizyolojik durumu: Uyku deprive

\section{EEG BULGULARI}

Tüm tetkik süresince temel biyoelektriksel aktivitenin pariyeto-oksipital yerleşimli 9-10 Hz frekansl, orta amplitüdlü alfa dalgalarından kurulu olduğu gözlenmiştir. Tanımlanan aktivitenin göz açmakla bloke olduğu dikkati çekmiştir.

Frontal elektrotlarda belirgin, simetrik, yüksek amplitüdlü, 4-5 Hz frekansta, diken, çoklu diken-yavaş dalga deşarjları sık aralıklarla izlenmiştir.

Çoklu dikenler ile video kaydında eş zamanlı izlenen jeneralize miyoklonik atımlar.

Yüzeyel NREM evreleri izlenmiş, uykunun fazik elemanları yeterli olarak değerlendirilmiştir.

Hiperventilasyon esnasında tanımlanan aktivitelerde artış izlenmiştir.

\section{YORUM}

Bu EEG anormaldir.

Anormalliklerin derecesi;

1- Primer bilateral hipersenkroni

2- Çoklu dikenler ile eş zamanlı miyoklonik jerkler

\section{KLINIK KORELASYON}

Klinik ve elektrofizyolojik bulgular jüvenil miyoklonik epilepsi tanısını desteklemektedir. 
ise klinisyenin sorusuna net şekilde cevap veren ifadeler kullanılabilir. Örneğin; "fokal veya lateralize anormallik tespit edilmedi", "epileptiform anormallik tespit edilmedi" ve "elektrografik nöbet ya da status epileptikusun kanıtı yok" gibi ifadeler eğer klinik istek açık ise klinik korelasyonda kullanılabilir. ${ }^{[2]}$

"Serebral disfonksiyon" tabiri raporu okuyan sağlık çalışanına çok güçlü bir ifade gibi gelebilir ve dolayısıyla klinik bağlamda gerçekçi olabilmesi için yeterli klinik bilgi mevcut olduğunda kullanılmalıdır. Örneğin; "kayıt, serebral fonksiyondaki hafif derecedeki bozuklukları gösterir" gibi bir cümle uygun olabilir. EEG raporlarında "ile uyumludur" terimi sıklıkla kullanılır. Açıkçası, pratikte herhangi bir EEG herhangi bir klinik tablo ile uyumlu olabilir. Dolayısıyla bu terim yararlı değildir ve birkaç istisna dışında kullanılmamalıdır. Bu tür EEG anormalliklerinin klinik durumla bağlantılı olarak sıklıkla bulunabileceği, ancak bunun mutlaka göstergesi olmadığı gerçeğinden söz etmek akıllıcadır. Sadece EEG çekimi sırasında eş zamanlı video kayıtlama ile gösterilen ve spesifik klinik ile ilişkili olduğu bilinen elektriksel bir anormallik gösterdiğinde bu ifade kullanılabilir. Böyle bir duruma, bilateral senkron $3 \mathrm{~Hz}$ diken dalga deşarjı ile birlikte tipik absans nöbetinin video kaydı esnasında izlenmesi örnek olabilir.

Tanısal klinik izlenim ile EEG bulgularının çelişkili göründüğü durumlarda, EEG raporunda tutarsızlığın bazı olası nedenleri raporda belirtilmelidir. Elektroensefalograf hiçbir koşulda ilaçta veya diğer klinik yaklaşımlarda değişiklik önermemelidir. Klinik korelasyon bir başka EEG önerilerek devam edebilir. Örneğin; “Klinik tablo göz önüne alındığında uyku kaydı faydalı olabilir" veya "Klinik nöbetten kısa bir süre sonra kayıt çekildiğinden, kalııı veya geçici yavaş dalga odağının belirlenmesinde takip EEG'ler yardımcı olabilir.".[1] Bazı yaygın senaryolar hastadan hastaya tutarlı olacaktır. Bireysel raporlama stilleri ve ifadeler değişkenlik gösterse de Tablo 2'de kullanılabilecek klinik korelasyon örnekleri verilmiştir. ${ }^{[2]}$

Son yıllarda dijital EEG cihazları ile eş zamanlı rapor yazma olanağı sağlayan bilgisayar ara yüz programları sunulmaktadır. 2013 yılında SCORE isimli programın ilk sürümü Avrupa'da yayınlanmış ve Uluslararası Klinik Nörofizyoloji Derneği ve ILAE tarafından onaylanarak önerilere açılımıştır. Elektroensefalograf EEG kaydında gözlediği aktiviteyi ILAE ve Amerikan Klinik Nörofizyoloji Derneği kılavuzlarına göre önceden belirlenmiş terimler listesinden seçim yapabilmekte ve en son aşamada rapor oluşturulmaktadır. Bu sayede serbest metin formatı yerine standart terminolojiyi içeren raporlar oluşturulmakta, ayrıca klinik araştırmalar için de veri tabanı sağlanmasına katkıda bulunulmaktadır. SCORE programı Avrupa Klinik Nörofizyoloji ve Uluslararası Klinik Nörofizyoloji Kongrelerinde tartışılmış, sonrasında ilk olarak Türkçe'nin de olduğu birçok dil çevirisi ile ticari olarak kullanıma sunulmuştur. Standart terminoloji nonkonvülzif status epileptikus kriterleri (Beniczky, 2013) ${ }^{[3]}$ geliştirilmesine de katkıda bulunmuştur. ${ }^{[10]}$ Ayrıca zemin aktivitesi, "intermittant" anormallikleri ve artefaktı otomatik olarak analiz eden ve bunun sonucunda rapor oluşturan yazılım programları da mevcuttur. ${ }^{[11]}$

Sonuç olarak; EEG raporlanmasında standart terminoloji ve düzenli bir yaklaşım izlenmeli, tüm sağlık çalışanlarının anlayabileceği bir dil kullanılmalı ve özellikle rapor "normal veya anormal" olarak ele alınarak bulguların klinik tabloya nasıl uyup uymadığı tartışı malıdır.

Tablo 3'te bir EEG raporu için standart bir düzen ana hatlarıyla verilmiştir. ${ }^{[1,2]}$ Tablo 4'te anormal bir EEG rapor örneği verilmiştir. ${ }^{[1,2]}$

\section{Hakem Değerlendirmesi- Dış bağımsız.}

Çıkar Çatışması- Yoktur.

Yazarlık Katkıları- Konsept: O.Y., B.Y.Ö., S.N.Y.; Dizayn: O.Y., B.Y.Ö., S.N.Y.; Literatür Arama: O.Y., B.Y.Ö.; Yazan: O.Y.

\section{Kaynaklar}

1. ACNS. Guideline 7: Guidelines for writing EEG reports. Journal of clinical neurophysiology: official publication of the American Electroencephalographic Society 2006;23(2):118. [CrossRef]

2. Tatum WO, Selioutski O, Ochoa JG, Clary HM, Cheek J, Drislane FW, et al. American Clinical Neurophysiology Society Guideline 7: Guidelines for EEG Reporting. Neurodiagn J 2016;56(4):28593. [CrossRef]

3. Beniczky S, Aurlien H, Brøgger JC, Hirsch LJ, Schomer DL, Trinka $E$, et al. Standardized computer-based organized reporting of EEG: SCORE - Second version. Clin Neurophysiol 2017;128(11):2334-46. [CrossRef]

4. Kaplan PW, Benbadis SR. How to write an EEG report: dos and don'ts. Neurology 2013;80(1 Suppl 1):S43-6. [CrossRef]

5. Bora İ, Yeni N. EEG atlası. 2nd ed, İstanbul: Nobel Tıp Kitabevleri; 2016. p. 475-82.

6. Kane N, Acharya J, Benickzy S, Caboclo L, Finnigan S, Kaplan PW, et al. A revised glossary of terms most commonly used by clinical electroencephalographers and updated proposal for the report format of the EEG findings. Revision 2017. Clin Neurophysiol Pract 2017;2:170-85. [CrossRef]

7. Fisher RS, Cross JH, French JA, Higurashi N, Hirsch E, Jansen $\mathrm{FE}$, et al. Operational classification of seizure types by the International League Against Epilepsy: Position Paper of the ILAE Commission for Classification and Terminology. Epilepsia 
2017;58(4):522-30. [CrossRef]

8. Blume WT, Lüders HO, Mizrahi E, Tassinari C, van Emde Boas W, Engel J., Glossary of descriptive terminology for ictal semiology: report of the ILAE task force on classification and terminology. Epilepsia 2001;42(9):1212-8. [CrossRef]

9. Marcuse LV, Fields MC, Yoo JJ. Rowan's Primer of EEG E-Book. Elsevier Health Sciences; 2015. p. 175-9. [CrossRef]
10. Brogger J, Eichele T, Aanestad E, Olberg H, Hjelland I, Aurlien H. Visual EEG reviewing times with SCORE EEG. Clin Neurophysiol Pract 2018;3:59-64. [CrossRef]

11. Shibasaki $H$, Nakamura $M$, Sugi $T$, Nishida $S$, Nagamine $T$, Ikeda A. Automatic interpretation and writing report of the adult waking electroencephalogram. Clinical neurophysiology 2014;125(6):1081-94. [CrossRef] 